\title{
Effect of the modification by titanium dioxide nanotubes with different structures on the fatigue response of Ti grade 2
}

\author{
Leonardo Contri Campanelli ${ }^{*}$, Paulo Sergio Carvalho Pereira da Silva ${ }^{a}$, Nilson Tadeu Camarinho \\ Oliveira $^{b}$, Claudemiro Bolfarini ${ }^{a}$ \\ a Department of Materials Engineering, Federal University of São Carlos, Rod. Washington Luís, \\ km. 235, 13565-905, São Carlos, SP, Brazil \\ ${ }^{b}$ Institute of Chemistry of São Carlos, University of São Paulo, Avenida Trabalhador Sãocarlense, 400, \\ 13566-590, São Carlos, SP, Brazil
}

Received: September 17, 2016; Revised: February 24, 2017; Accepted: May 1, 2017.

\begin{abstract}
Nanotechnology is seeing as having potential to raise benefits to several research and application areas. Recently materials with nanostructured surfaces of nanopores, nanotubes and nanowires have become an important investigation field, since their chemical and physical properties may be substantially different from those of the corresponding substrate. In face of the necessity of assuring that such modifications are not deleterious to the mechanical behavior, the purpose of this work was to evaluate the fatigue performance of CP-Ti grade 2 with the surface modified by the formation of nanotubes on their different crystalline structures. The nanotubes layers were produced by anodic oxidation using a potential of $20 \mathrm{~V}$ during $1 \mathrm{~h}$ and a solution of glycerol, $\mathrm{H}_{2} \mathrm{O}$ and $\mathrm{NaF}$, and analyzed by scanning electron microscopy. In order to obtain the anatase and rutile structures, annealing treatments were respectively performed at $450^{\circ} \mathrm{C}$ and $650^{\circ} \mathrm{C}$. The axial fatigue tests were conducted in physiological solution at $37^{\circ} \mathrm{C}$ following the stepwise load increase approach. When compared to the material without surface modification (polished surface), the results showed that the anatase phase did not affect the fatigue response, maintaining the fracture stress in $500 \mathrm{MPa}$, whereas the rutile phase caused a decrease to $450 \mathrm{MPa}$.
\end{abstract}

Keywords: titanium, surface modification, nanotubes, fatigue

\section{Introduction}

Nanotechnology has been explored as a tool for the surface modification of Ti and its alloys for implants applications, for instance with the growth of nanotubular and nanoporous oxide layers $^{1,2}$. It has been extensively shown that nano-scale oxide coatings are able to increase the surface bioactivity and consequently the osseointegration phenomenon ${ }^{3}$. Salou et al. ${ }^{4}$ studied the osseointegration behavior of Ti-6Al-4V implants with different surface morphologies after four weeks of implantation in the femoral condyle of rabbits. By these in vivo tests, it was testified that the nano-modified surface resulted in improved osseointegration when compared to the modified surfaces at the micrometer level. Within the most cost-effective possibilities to achieve nano-scale oxide coatings is the anodic oxidation process, which allows the growth of different morphologies according to the electrolyte composition. When fluoride-containing electrolytes are used, it is probable that self-organized and highly ordered layers of nanotubes arrays are obtained, typically with an amorphous structure ${ }^{5}$. It is known that the crystal structure of these layers can be modified by post-annealing treatments, inducing the enhanced formation of a hydroxyapatite layer ${ }^{6}$.

*e-mail: leoccampa@hotmail.com
Due to the great sensitiveness to the surface condition, the fatigue performance is always a great concern when surface modification of implants is performed. In the case of a nanotubes coating, Bortolan et al. ${ }^{7}$ did not observe a deleterious effect of the coating itself on the fatigue response of Ti-6Al-4V, which was mainly attributed to the nano-scale thickness of the modified layer. The amorphous structure plays an important role, since it allows the elastic deformation of the oxide layer in a degree sufficient to avoid the generation of surface cracks ${ }^{8}$. However, when the amorphous structure is changed to a crystalline one, the introduction of residual stresses may become the main factor controlling the fatigue behavior. Apachitei et al. ${ }^{9}$ verified a significant influence of residual stresses on the fatigue response of plasma electrolytic oxidized Ti-6Al-4V and Ti-6Al-7Nb with coatings of several micrometers of thickness.

The aim of this work is a preliminary assessment of the fatigue performance of $\mathrm{CP}$-Ti coated with an array of $\mathrm{TiO}_{2}$ nanotubes in different crystal structures.

\section{Materials and Methods}

The material employed in this work was rounded bars of CP-Ti (grade 2) in accordance with the requirements of 
ASTM F67 standard. Cylindrical fatigue specimens were machined following the geometrical aspects of ASTM E466 standard, grinded with silicon carbide emery papers and polished with diamond pastes up to $1 \mu \mathrm{m}$. Anodic oxidation was therefore employed to obtain the nanotubes layer using an Agilent 6575A-J07DC power supply and a two electrode system, with the $\mathrm{Ti}$ as the working electrode and a 304 stainless steel plate as the counter electrode. A solution of glycerol, $\mathrm{H}_{2} \mathrm{O}(50: 50 \mathrm{vol} . \%)$ and $0.31 \mathrm{M} \mathrm{NaF}$ was used as the working electrolyte and a potential of $20 \mathrm{~V}$ was applied during $1 \mathrm{~h}$ at room temperature, without stirring ${ }^{10}$.

In order to change the oxide structure, annealing treatments in air were performed during $3 \mathrm{~h}$ in the temperatures of 450 and $650^{\circ} \mathrm{C}$, with subsequent air cooling. The surface morphologies were evaluated by scanning electron microscopy (SEM) in a FEI Magellan 400 L microscope. X-ray diffraction (XRD) analyses were conducted in a Siemens D5005 diffractometer with $\mathrm{CuK} \alpha$ radiation. The phases were identified by matching the diffractograms to the JCPDS files and the XRD patterns were indexed through the Crystallographica Search-Match 2.1.1.1 software.

Axial fatigue tests were conducted in a MTS Bionix servo hydraulic testing machine, employing a simple physiological solution $(9 \mathrm{~g} / \mathrm{L} \mathrm{NaCl})$ at $37^{\circ} \mathrm{C}$, a frequency of $10 \mathrm{~Hz}$ and a stress ratio $\mathrm{R}=0.1$. Stepwise load increase tests were applied, in which the maximum stress started at $150 \mathrm{MPa}$ and was increased by steps of $50 \mathrm{MPa}$ every $5 \times 10^{4}$ cycles until the rupture. This method has been used as a low-time consuming approach aiming at the preliminary evaluation of the surface modification effect on the fatigue response, and therefore three replicates were adopted to provide the arithmetic mean of the fatigue fracture stress.

\section{Results and Discussion}

Figure 1a brings a SEM micrograph of CP-Ti after anodization in the conditions aforementioned. The surface

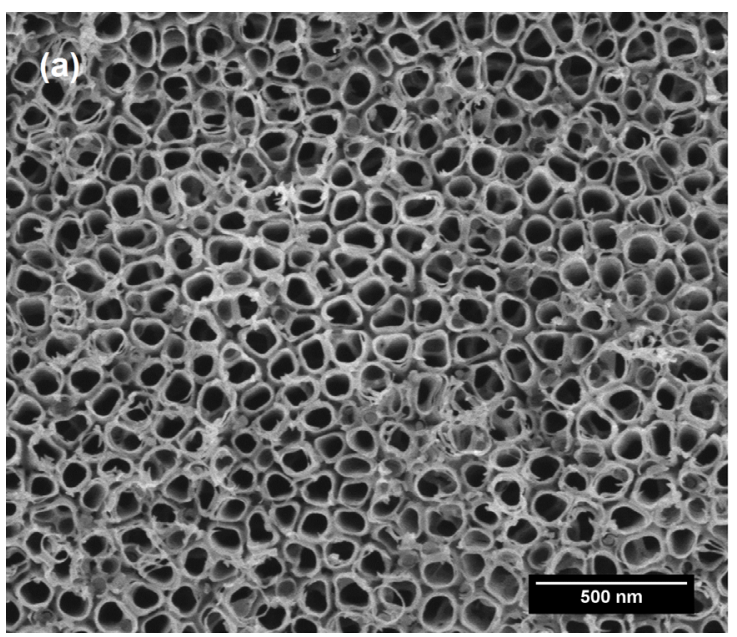

typically consists of a well-organized and homogeneous arrangement of nanotubes with, under the employed conditions, an average diameter of $90 \mathrm{~nm}$. It is known that the underlying microstructure of CP-Ti is fully comprised by alpha phase, in which the growth of nanotubes proceeds during the anodization process without any problems ${ }^{11}$. In Figure $1 b$, the cross-section micrograph of a mechanically scratched region also shows an organized arrangement of nanotubes, allowing the determination of their average length of approximately $1 \mu \mathrm{m}$. It is noteworthy the undulations observed in the substrate when the nanotubes layer was removed, which are not expected to work as mechanical notches due to their nano-scale dimension.

It is a well-established concept that the anodic oxidation treatment results in an amorphous oxide structure over the CP-Ti substrate. When the anodized samples were heat treated at both temperatures, no changes in the nanotubes morphologies were detected. Nevertheless, the oxide structures were confirmed to be changed into crystalline anatase and rutile at respectively $450^{\circ} \mathrm{C}$ and $650^{\circ} \mathrm{C}$. These results are in accordance to the structural transformation by annealing of $\mathrm{TiO}_{2}$ nanotubes layer in $\mathrm{Ti}$ systems, as mentioned in the literature ${ }^{2,7,12}$. An example of these findings is shown in Figure 2, where the micrograph of the nanotubes layer after $450^{\circ} \mathrm{C}$ treatment is presented, and the XRD pattern of such condition is compared with the one of the as-formed nanotubes condition. It is clear that the oxide layer maintains the morphological features after the heat treatment and that the anatase phase is formed in this case, which were similarly noted after the $650^{\circ} \mathrm{C}$ treatment except for the rutile formation predominance.

The fatigue performance of the $450^{\circ} \mathrm{C}$ annealed nanotubes layer characterized by the stepwise load increase tests is presented in Figure 3. The maximum stress and the resultant maximum displacement are plotted against the number of cycles. If tangent lines are hypothetically plotted in the displacement curves, the slope of these lines

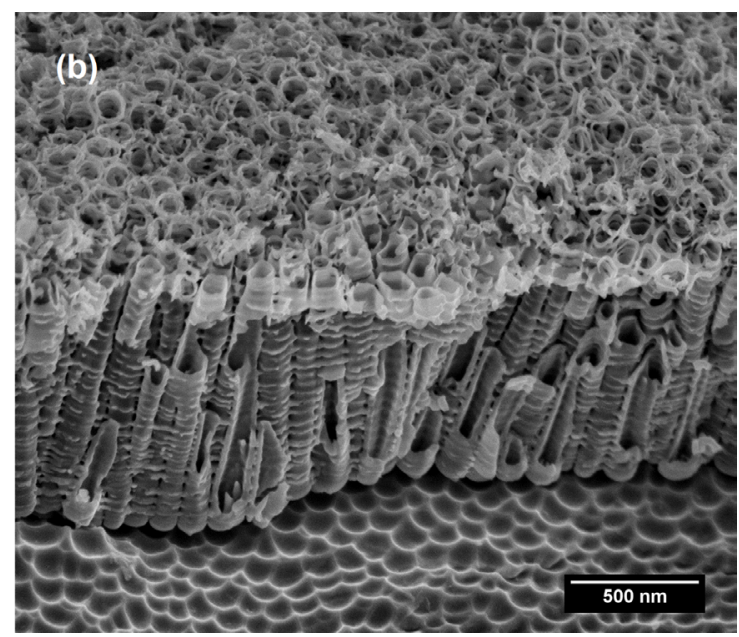

Figure 1. SEM micrographs of CP-Ti after anodization at 20V and $1 \mathrm{~h}$ : (a) top view and (b) cross-section. 

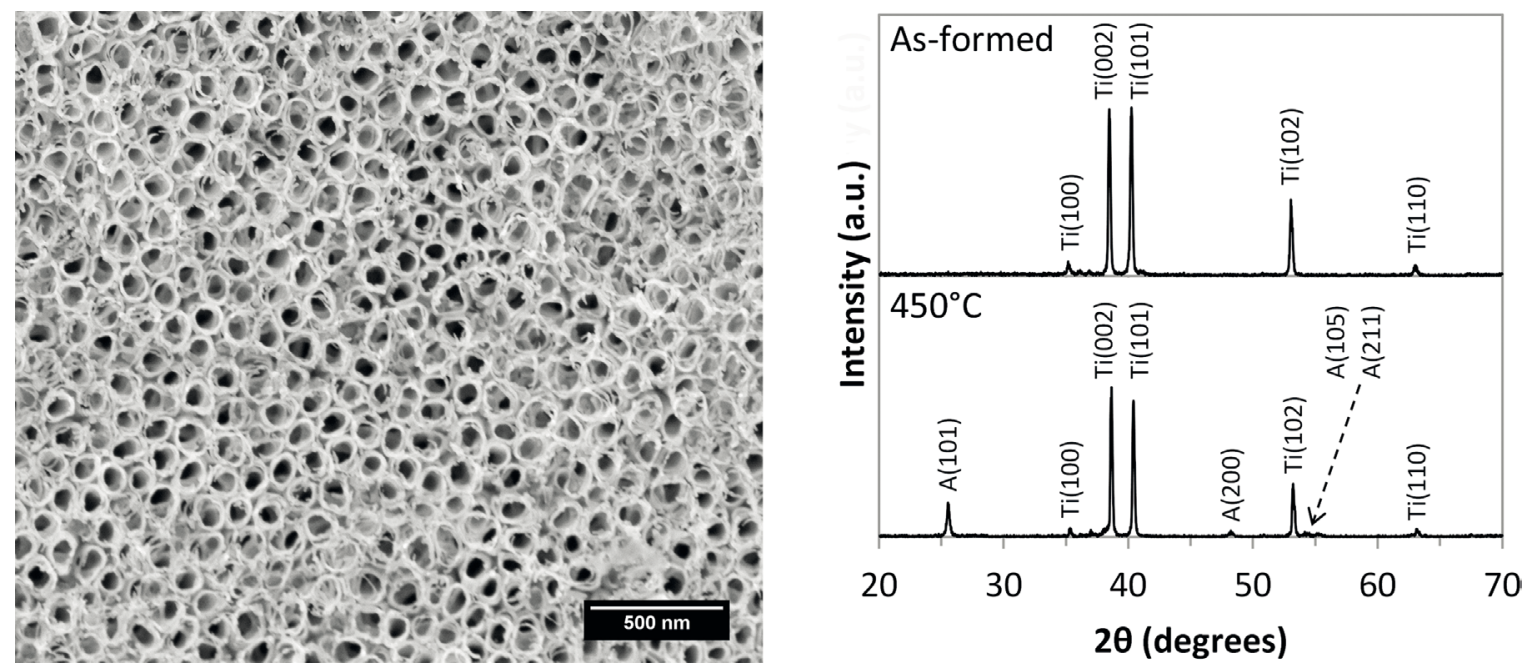

Figure 2. SEM micrograph and XRD pattern of the nanotubes layer after annealing at $450^{\circ} \mathrm{C}$, along with XRD pattern of the as-formed condition.

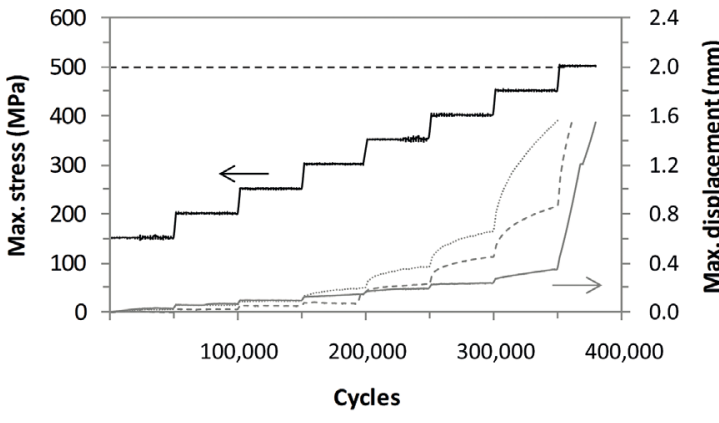

CP1 - - - - CP2 ……….... CP3

Figure 3. Stepwise load increase plot for the specimens annealed at $450^{\circ} \mathrm{C}$.

is significantly increased in the stress levels above $500 \mathrm{MPa}$ for two specimens (and above $450 \mathrm{MPa}$ for one specimen), which may indicate that macro-crack nucleation may have occurred. All specimens, however, failed with a few cycles (lower than 30,000) in the stress of $500 \mathrm{MPa}$. In the case of the specimens treated at $650^{\circ} \mathrm{C}$, the curves presented in Figure 4 reveal that the displacement increase, as well as the specimens fracture, occurs with a few cycles (lower than $25,000)$ in the stress of $450 \mathrm{MPa}$.

It is important to note that no microstructural alterations of the CP-Ti substrate were verified after the heat treatments. In addition to the fact that the morphologies and dimensions of the nanotubes layers were similar prior and after the annealing treatments, the changes in the fatigue performance may be explained by the differences of the oxide crystalline structure. A summary of the fatigue fracture results in all surface conditions is found in Figure 5. The average fracture stress of the amorphous and $450^{\circ} \mathrm{C}$ treated conditions is the same of the polished surface, but a reduction, albeit small, is clear when the $650^{\circ} \mathrm{C}$ treated condition is considered (note the error bars in all conditions).

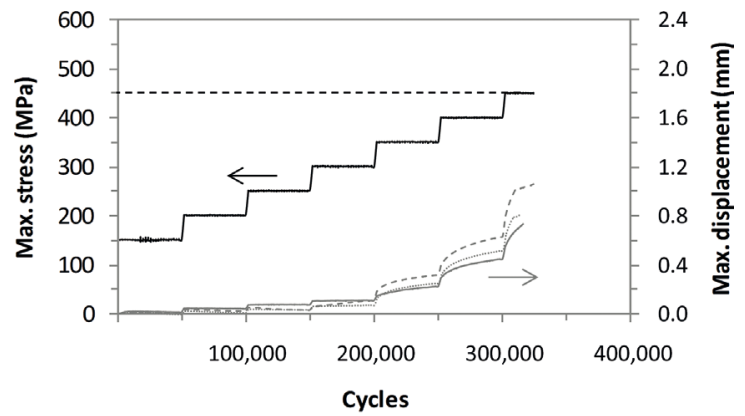

CP3

Figure 4. Stepwise load increase plot for the specimens annealed at $650^{\circ} \mathrm{C}$.

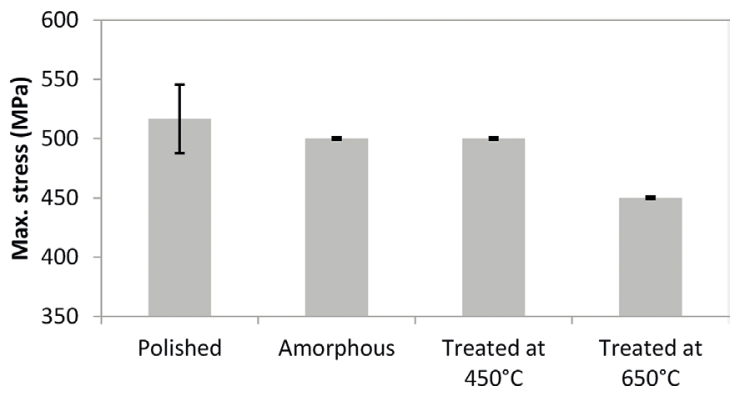

Figure 5. Summary of the fatigue results obtained with the stepwise load increase tests.

One reason for the reduced fatigue performance of coated specimens could be the generation of cracks in the nanotubes oxide layer under cyclic loading. For the amorphous structure of the oxide coating, a previous work of Campanelli et al. ${ }^{8}$ on Ti-6Al-4V verified the absence of cracks after the fatigue tests. This was attributed to an elastic behavior of the oxide layer sufficient to allow the deformation and prevent the formation of cracks. Hence, in the absence of cracks, the small dimension of the coating led to a negligible influence on the 

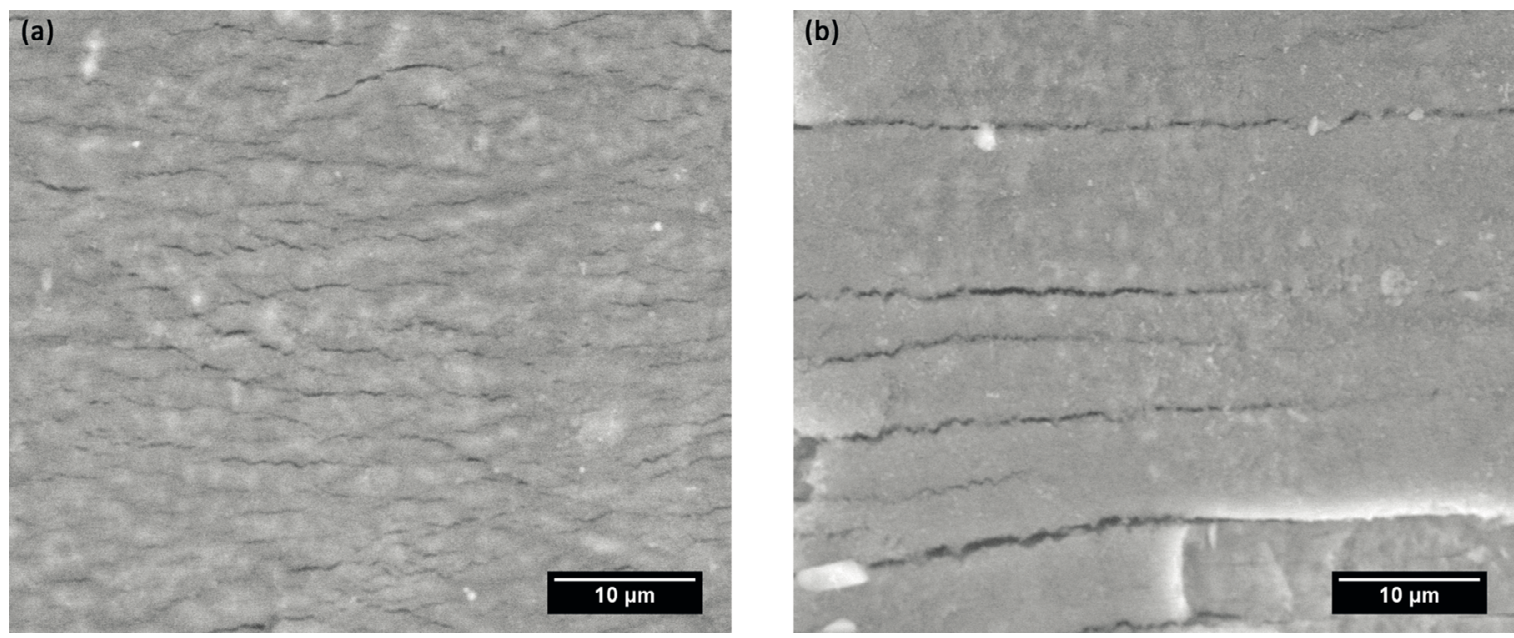

Figure 6. SEM micrographs of the nanotubes layer after the fatigue tests: (a) annealed at $450^{\circ} \mathrm{C}$ (anatase structure) and (b) annealed at $650^{\circ} \mathrm{C}$ (rutile structure).

fatigue response. In the present work, the crystallization of the oxide may have changed the deformation behavior since cracks were detected after the fatigue tests. As presented in Figure 6, several cracks can be observed in both specimens treated at 450 and $650^{\circ} \mathrm{C}$.

However, a fundamental difference is noticeable between the cracks pattern. In the case of rutile, fewer and larger cracks are observed in contrast to a large number of small cracks in the case of anatase. This can be attributed to the formation of residual stresses, which are tensile for the rutile and compressive for the anatase structure ${ }^{13}$. In consequence, in the rutile layer the cracks grew reaching a critical size before the cracks in the anatase layer for the same substrate material. Final fracture should therefore occur under smaller stresses in the case of rutile, as the fatigue results show in Figure 5. Such observation clearly shows the necessity of a careful evaluation in the selection of surface modification treatments that are expected to improve the osseointegration behavior, since the solely change of the oxide structure, even without modifying the nanotubes dimensions, may affect the fatigue behavior.

\section{Conclusions}

A well-organized and homogeneous arrangement of nanotubes with $90 \mathrm{~nm}$ diameter and $1 \mu \mathrm{m}$ length was obtained on CP-Ti. Subsequent crystallization of the oxide layer into anatase and rutile through annealing did not alter the morphological features. The fatigue study based on the stepwise load increase approach revealed that the surface modification with amorphous and anatase phase resulted in a similar fracture stress of $500 \mathrm{MPa}$, but a reduction to $450 \mathrm{MPa}$ was observed in the presence of rutile phase, suggesting caution in the design of surface modified implants.

\section{Acknowledgements}

The authors are grateful to the financial support from FAPESP (grant 2012/01652-9 and scholarships 2013/04423-3 and 2016/12995-5).

\section{References}

1. Kapusta-Kołodziej J, Zaraska L, Sulka GD. Nanoporous anodic titania observed at the bottom side of the oxide layer. Applied Surface Science. 2014;315:268-273.

2. Oliveira NTC, Verdério JF, Bolfarini C. Obtaining self-organized nanotubes on biomedical Ti-Mo alloys. Electrochemistry Communications. 2013;35:139-141.

3. Saji VS, Choe HC, Brantley WA.An electrochemical study on self-ordered nanoporous and nanotubular oxide on Ti-35Nb-5Ta-7Zr alloy for biomedical applications. Acta Biomaterialia. 2009;5(6):2303-2310.

4. Salou L, Hoornaert A, Louarn G, Layrolle P. Enhanced osseointegration of titanium implants with nanostructured surfaces: An experimental study in rabbits. Acta Biomaterialia. 2015;11:494-502.

5. Kulkarni M, Mazare A, Gongadze E, Perutkova Š, Kralj-Iglič V, Milošev I, et al. Titanium nanostructures for biomedical applications. Nanotechnology. 2015;26(6):062002.

6. Minagar S, Berndt CC, Wang J, Ivanova E, Wen C. A review of the application of anodization for the fabrication of nanotubes on metal implant surfaces. Acta Biomaterialia. 2012;8(8):2875-2888.

7. Bortolan CC, Campanelli LC, Bolfarini C, Oliveira NTC. Fatigue strength of Ti-6Al-4V alloy with surface modified by $\mathrm{TiO}_{2}$ nanotubes formation. Materials Letters. 2016;177:46-49.

8. Campanelli LC, Bortolan CC, da Silva PS, Bolfarini C, Oliveira NT. Effect of an amorphous titania nanotubes coating on the fatigue and corrosion behaviors of the biomedical Ti-6Al-4V and Ti-6Al-7Nb alloys. Journal of the Mechanical Behavior of Biomedical Materials. 2017;65:542-551.

9. Apachitei I, Lonyuk B, Fratila-Apachitei LE, Zhou J, Duszczyk J. Fatigue response of porous coated titanium biomedical alloys. Scripta Materialia. 2009;61(2):113-116. 
10. Córdoba-Torres P, Oliveira NTC, Bolfarini C, Roche V, Nogueira $\mathrm{RP}$. Electrochemical impedance analysis of $\mathrm{TiO}_{2}$ nanotube porous layers based on an alternative representation of impedance data. Journal of Electroanalytical Chemistry. 2015;737:54-64.

11. Macak JM, Tsuchiya H, Taveira L, Ghicov A, Schmuki P. Self-organized nanotubular oxide layers on Ti-6Al-7Nb and Ti-6Al-4V formed by anodization in NH4F solutions. Journal of Biomedical Materials Research Part A. 2005;75(4):928-933.
12. Luo B, Yang H, Liu S, Fu W, Sun P, Yuan M, et al. Fabrication and characterization of self-organized mixed oxide nanotube arrays by electrochemical anodization of Ti-6Al-4V alloy. Materials Letters. 2008;62(30):4512-4515.

13. Khan RHU, Yerokhin AL, Matthews A. Structural characteristics and residual stresses in oxide films produced on Ti by pulsed unipolar plasma electrolytic oxidation. Philosophical Magazine. 2008;88(6):795-807. 